\title{
To readers
}

This book is designed as a linguistic introduction to Middle English for undergraduate students who have already encountered the language, perhaps through reading Chaucer's works or having undertaken a general 'survey' course on the history of the English language. We have attempted to make the book a bridge between elementary surveys of the kind to be found in beginners' readers and more sophisticated (and theoretically oriented) work; thus in the last chapter we point forward to issues which are part of recent scholarly debate. Our view is that it is important for all students, as colleagues in the discipline, to be aware of current controversies; however, we have tried to avoid such controversies in the body of the book so that not too strong a 'party-line' is pushed. Even so, it would be foolish to deny that there is an overarching approach, which may be defined as linking concerns often described as 'linguistic' (theory-centred) with 'philological' (text-centred) ones.

We envisage our book being used, at an early stage, as part of an undergraduate Honours course on Middle English. In order to enhance its usefulness (and indeed to keep overall costs down) we have supplied a reader of illustrative texts, but ideally students will supplement this with other collections. We especially recommend Burnley 1992.

The authors would like to acknowledge with gratitude the patience and tolerance of Sarah Edwards and James Dale. We are also much indebted to the very helpful and detailed comments on the first draft made by Donka Minkova and Heinz Giegerich, which saved us from many infelicities, drew attention to flaws, and were invaluable in clarifying and correcting our arguments. We were also very grateful for early sight of parts of the companion ETOTEL volume on Old English, by Richard Hogg. However, we take full responsibility for any errors of omission or commission which remain.

Although we collaborated closely in the writing of the book, JJS was primarily responsible for Chapters 1 to 7 ; $\mathrm{SCH}$ undertook the editing and annotation of the Appendix of Texts, and supplied textual material at various points elsewhere. 